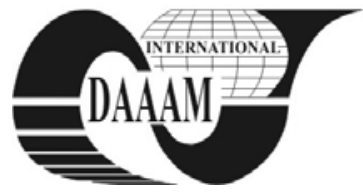

\title{
MODELING AND EXPERIMENTAL STUDY OF TANGENTIAL CUTTING FORCE IN DRY TURNING OF TI-6AL-4V ALLOY
}

\author{
UPADHYAY, V[ikas]; JAIN, P[ramod] K[umar] \& MEHTA, N[arinder] K[umar]
}

\begin{abstract}
In the present work, an attempt has been made to investigate the effect of cutting parameters on the tangential cutting force in dry turning of Ti-6Al-4V alloy and to subsequently develop a predictive regression model. The experiments were conducted as per design matrix of Face centered cube design with three replications of centre point. Tangential cutting force decreases with increase in cutting speed from $50 \mathrm{~m} / \mathrm{min}$ to $90 \mathrm{~m} / \mathrm{min}$ but increases with increase in cutting speed from 90 to $130 \mathrm{~m} / \mathrm{min}$ due to rapid wear of tool material.
\end{abstract}

Key words: tangential cutting force, dry turning, regression model, titanium alloy

\section{INTRODUCTION}

Ti-6Al-4V alloy finds wide application in modern manufacturing due to its exceptional corrosion resistance and high strength to weight ratio which is maintained even at elevated temperatures (Ezugwu \& Wang, 1997). However developments in the application of Ti-6Al-4V have not kept pace with other materials due to its high initial cost and difficulty in machining. Its low thermal conductivity leads to high temperature generation at the chip tool interface and strong alloying tendency at prevailing cutting temperature results in welding, galling and smearing along with rapid destruction of the cutting tool resulting in short tool life (Donachie, 2000). Machining of this alloy produces very thin chips. As a consequence small tool-chip interface area causes high stresses and temperature on the tip of the tool (Machado \& Wallbank, 1990). Apart from these problems, shear strain in the chip is not uniform; rather, it is confined in a narrow band between the segments resulting in serrated chips and often causes serious vibrations which limit the material removal rate and affect the tool life (Komanduri \& Turkovich, 1981, Hua \& Shivpuri, 2004).

Cutting force is one of the important parameter to describe the machinability of a material and power requirement in machining. Hong et al (2001) reported that tangential cutting force $\left(\mathrm{F}_{\mathrm{z}}\right)$ decreases with increase in cutting speed from $60 \mathrm{~m} / \mathrm{min}$ to $250 \mathrm{~m} / \mathrm{min}$ under dry and cryogenic cutting. Ezugwu et al. (2005) studied cutting forces under conventional coolant supply and argon enriched environment. They reported that tangential cutting force decreases with increase in cutting speed upto $120 \mathrm{~m} / \mathrm{min}$ and then increases at speed of 130 $\mathrm{m} / \mathrm{min}$ under conventional coolant supply, whereas tangential cutting force increases with the cutting speed beyond 110 $\mathrm{m} / \mathrm{min}$ under argon enriched environment. Sun et al. (2009) reported that tangential cutting force in dry turning increases with cutting speed up to $21 \mathrm{~m} / \mathrm{min}$ and then decreases from 21 to $57 \mathrm{~m} / \mathrm{min}$. Tangential cutting force increases by $10 \mathrm{~N}$ when cutting speed is increased from 57 to $75 \mathrm{~m} / \mathrm{min}$, then remains constant as the speed is increased from 75 to $113 \mathrm{~m} / \mathrm{min}$ and finally decreases beyond $113 \mathrm{~m} / \mathrm{min}$. From their study, it can be concluded that there is no critical speed in case of dry turning below which tool material manintains it hardness and above which tool softening occurs as observed by Ezugwu et al. (2005) with conventional coolant supply and argon enriched environment. However under identical cutting conditions, more heat will remain at the tool tip in dry turning as compared to wet and hence, there is more chances of tool softening. So, it requires further study of the tangential cutting force in dry turning of this alloy to determine the occurrence of tool softening. In the present study, dry turning of Ti-6Al-4V alloy is carried out to determine the variation of tangential cutting force with cutting speed and to investigate the presence of critical cutting speed.

\section{EXPERIMENTAL STUDY}

\subsection{Experimental procedure}

The experimental study is conducted on Ti-6Al-4V alloy under dry cutting condition. Rigid, high power precision lathe (model: NH22; Make: HMT, India) equipped with specially designed experimental set-up is used for experimental work. Work-piece is held between three jaw chuck and revolving centre for increasing the rigidity of machining system. DCLNR 2525 M12 tool holder is used to hold the CNMG 120408 tool bit of cemented carbide (ISO S-grade). The tool angles are as follows: back rake angle $=-6^{\circ}$, side rake angle $=-6^{\circ}$, principal cutting edge angle $=95$ end cutting edge angle $=5 \circ$, nose radius $=0.8 \mathrm{~mm}$. The tangential cutting force was measured using Kistler ${ }^{\circledR}$ piezoelectric dynamometer (model 9257B). The charge generated at the dynamometer was amplified using charge amplifier (Kistler multichannel charge amplifier Type 5070). The amplified signal was acquired and stored in computer using Dyno Ware software for further analysis. Machining operations were carried out at various cutting parameters as shown in Table 1. Fresh cutting edge is used in each experimental run to mitigate the effect of tool wear.

\subsection{Experimental Design}

Experiments were designed according to the face centered central composite design or face-centered cube (FCC) of Response Surface Methodology (RSM). Experimental design involves variation of three factors (cutting speed, feed rate and depth of cut) at three levels as mentioned in Tab. 1. This requires a total of 17 experimental runs including three replications of centre point. The face centered cube does not require as many centre points as in spherical central composite design as two or three centre points are sufficient to provide good variance of prediction in experimental region (Montgomery, 2007). Tab. 2. shows the parametric combination for various run of experiments.

\begin{tabular}{|l|l|l|l|l|}
\hline Variable & \multirow{2}{*}{ Unit } & \multicolumn{3}{|c|}{ Level } \\
\cline { 3 - 5 } & & 1 & 2 & 3 \\
\hline Cutting Speed (A) & $\mathrm{m} / \mathrm{min}$ & 50 & 90 & 130 \\
\hline Feed rate (B) & $\mathrm{mm} / \mathrm{rev}$ & 0.16 & 0.20 & 0.24 \\
\hline Depth of cut (C) & $\mathrm{mm}$ & 0.5 & 0.75 & 1 \\
\hline
\end{tabular}

Tab. 1. Level of independent variables for turning 


\section{RESULTS AND DISCUSSIONS}

The regression model for the tangential cutting force is developed with the help of Design-Expert 6.0.8 software. Regression model in terms of actual value is described by equation (1)

$$
\begin{aligned}
\mathrm{F}_{\mathrm{z}}= & -74.82028-4.52764 * \mathrm{~A}+3677.39387 * \mathrm{~B}+25.7 * \mathrm{C} \\
& +0.024292 * \mathrm{~A}^{2}-9145.04717 * \mathrm{~B}^{2}+1437.5 * \mathrm{~B} * \mathrm{C}
\end{aligned}
$$

The various $\mathrm{R}^{2}$ statistics of the developed regression model are given in Tab. 3. The $\mathrm{R}^{2}$ value of model is 0.9954 which indicates that the model can explain $99.54 \%$ of total variations. 0.9926 value of Adjusted $\mathrm{R}^{2}$ indicates that the $99.26 \%$ of the total variability can be explained by the model after considering the significant factors. Predicted $\mathrm{R}^{2}$ of 0.9859 is in good agreement with the Adjusted $\mathrm{R}^{2}$ of 0.9926 and indicates that the model can explain $98.59 \%$ of total variability in new data.

Variation of tangential cutting force with feed rate, depth of cut and cutting speed is shown in Fig. 1. It is evident that tangential cutting force increases with increase in depth of cut and feed rate due to increased amount of material to be removed from the material. Increase in cutting speed from $50 \mathrm{~m} / \mathrm{min}$ to 90 $\mathrm{m} / \mathrm{min}$ results in decrease of magnitude of tangential cuting force. It happens due to decrease in heat dissipation time at high cutting speed leading to rise in temperature at tool work piece interface resulting in drop of shear strength in flow zone of work piece material. Further increase in cutting speed to 130 $\mathrm{m} / \mathrm{min}$ results in increase in magnitude of cutting force component. This may be attributed to rapid increase in cutting temperature at tool chip interface which results in softening/rapid wear of tool material.

The tool used in experimental work has same cutting edge angles and rake angles as used by Ezugwu et al. (2005) but different nose radius. However the cutting geometry used by Sun et al. (2009) is different from present work and thus might have lead to less heat generation at the tool tip. So, further

\begin{tabular}{|c|c|c|c|c|c|}
\hline $\begin{array}{c}\text { Std. } \\
\text { Order }\end{array}$ & Type & $\begin{array}{c}\text { Cutting } \\
\text { Speed } \\
(\mathrm{m} / \mathrm{min})\end{array}$ & $\begin{array}{c}\text { Feed rate } \\
(\mathrm{mm} / \mathrm{rev})\end{array}$ & $\begin{array}{c}\text { Depth of } \\
\text { cut }(\mathrm{mm})\end{array}$ & $\begin{array}{c}\text { Cutting } \\
\text { Force (N) }\end{array}$ \\
\hline 1 & Fact & $-1(50)$ & $-1(0.16)$ & $-1(0.50)$ & 241 \\
\hline 2 & Fact & $1(130)$ & $-1(0.16)$ & $-1(0.50)$ & 231 \\
\hline 3 & Fact & $-1(50)$ & $1(0.24)$ & $-1(0.50)$ & 303 \\
\hline 4 & Fact & $1(130)$ & $1(0.24)$ & $-1(0.50)$ & 291 \\
\hline 5 & Fact & $-1(50)$ & $-1(0.16)$ & $1(1.00)$ & 364 \\
\hline 6 & Fact & $1(130)$ & $-1(0.16)$ & $1(1.00)$ & 361 \\
\hline 7 & Fact & $-1(50)$ & $1(0.24)$ & $1(1.00)$ & 494 \\
\hline 8 & Fact & $1(130)$ & $1(0.24)$ & $1(1.00)$ & 468 \\
\hline 9 & Axial & $-1(50)$ & $0(0.20)$ & $0(0.75)$ & 360 \\
\hline 10 & Axial & $1(130)$ & $0(0.20)$ & $0(0.75)$ & 349 \\
\hline 11 & Axial & $0(90)$ & $-1(0.16)$ & $0(0.75)$ & 261 \\
\hline 12 & Axial & $0(90)$ & $1(0.24)$ & $0(0.75)$ & 341 \\
\hline 13 & Axial & $0(90)$ & $0(0.20)$ & $-1(0.50)$ & 244 \\
\hline 14 & Axial & $0(90)$ & $0(0.20)$ & $1(1.00)$ & 406 \\
\hline 15 & Center & $0(90)$ & $0(0.20)$ & $0(0.75)$ & 316 \\
\hline 16 & Center & $0(90)$ & $0(0.20)$ & $0(0.75)$ & 324 \\
\hline 17 & Center & $0(90)$ & $0(0.20)$ & $0(0.75)$ & 312 \\
\hline
\end{tabular}

Tab. 2. Face centered cube design along with the parameter values for different run

\begin{tabular}{|l|l|}
\hline R-Squared & 0.9954 \\
\hline Adj R-Squared & 0.9926 \\
\hline Pred R-Squared & 0.9859 \\
\hline
\end{tabular}

Tab. 3. Various R squared statistics

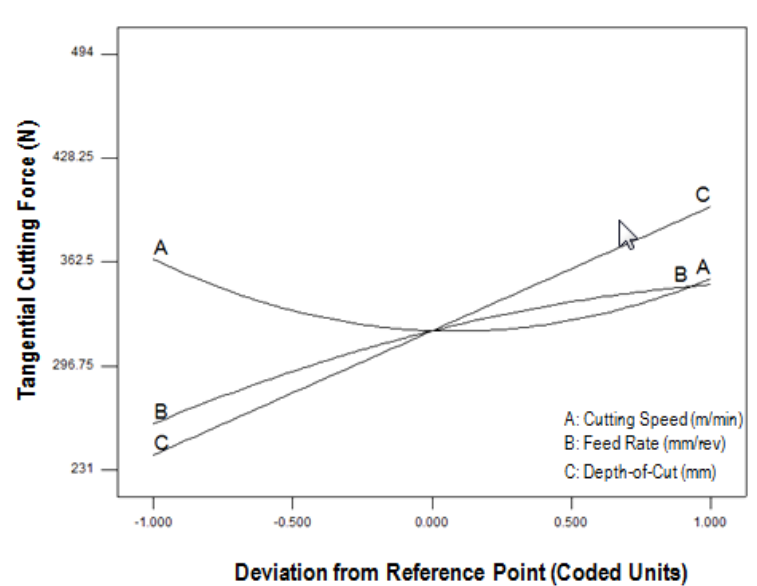

Fig. 1. Effect of cutting speed, feed rate and depth of cut on tangential cutting force

investigations are required to study the effect of tool geometry on cutting force.

\section{CONCLUSION AND FUTURE SCOPE}

Based on the experimental data obtained it can be concluded that tangential cutting force is affected the most by the depth of cut. Further, there is a critical speed below which the tangential cutting force decreases with the increase of speed due to softening of workpiece material. However, at cutting speeds beyond the critical value the tangential cutting force begins to increase, thereby indicating the onset of condition in which heat concentration at the tool tip predominates over workpiece softening due to poor thermal conductivity of workpiece material resulting in rapid tool wear. Detailed investigation of this phenomenon covering a wide range of variables including tool geometry is necessary for developing a better understanding of the machinability of Ti-6Al-4V alloy.

\section{REFERENCES}

Donachie, M. J. Jr. (2000). Titanium: A Technical Guide, second edition, ASM International, USA.

Ezugwu, E. O. \& Wang, Z. M. (1997). Titanium alloys and their machinability- a review. Journal of Materials Processing Technology, 68, pp. 262-274

Ezugwu, E.O.; Da Silva, R. B.; Bonney J. \& Machado A.R. (2005). The effect of argon enriched environment in high speed machining of titanium alloy, Tribology Transactions, 48, pp. 18-23

Hong, S.Y.; Ding Y. \& Jeong, Woo-cheol (2001). Friction and cutting forces in cryogenic machining of Ti-6Al-4V. Int. J. of Machine Tool and Manufacture, 41, pp. 2271-2285

Hua, J. \& Shivpuri, R. (2004). Prediction of chip morphology and segmentation during the machining of Titanium alloys. Journal of Materials Processing Technology, 150, pp.124133

Komanduri, R. \& Turkovich, B.F.V. (1981). New observations on the mechanism of Chip formation when machining Titanium alloys, Wear, 69, pp. 179-188

Machado, A. R. \& Wallbank, J. (1990). Machining of titanium and its alloys-a review, Proc. IMechE Part B: Journal of Engineering Manufacture, 204, pp. 53-60

Montgomery, D.C. (2007). Design and Analysis of Experiments, fifth edition, Wiley, India

Sun, S.; Brandt, M. \& Dargusch, M.S. (2009). Characteristics of cutting forces and chip formation in machining of titanium alloys. Int. J. of Machine Tools and Manufacture, 49, pp. 561-568 